\begin{tabular}{|c|c|c|}
\hline $\operatorname{INF}_{P \cup B L I C A T I O N}$ & $\begin{array}{l}\text { International Journal of Advanced Engineering, Management and Science } \\
\text { (IJAEMS) } \\
\text { ISSN: 2454-1311 } \\
\text { Vol-7, Issue-3; Mar, } 2021 \\
\text { Journal Home Page Available: } \underline{\text { https://ijaems.com/ }} \\
\text { Journal DOI: } \text { https://dx.doi.org/10.22161/ijaems } \\
\text { Article DOI: https://dx.doi.org/10.22161/ijaems.73.10 }\end{array}$ & (1) \\
\hline
\end{tabular}

\title{
Analysis Industrial Robot Arm with Matlab and RoboAnalyzer
}

\author{
Arif Krisbudiman $^{1}$, Tsani Hendro Nugroho ${ }^{2}$, Ahmad Musthofa ${ }^{3}$
}

${ }^{1}$ Center for Machine technology, production, and automation, Agency for Technology Assessment and application, Indonesia; Faculty of Industrial Engineering, University of Pamulang, Indonesia

${ }^{2}$ Intelligent Machine Laboratory, Center for Machine technology, production, and automation, Agency for Technology Assessment and application, Indonesia

${ }^{3}$ Automation Laboratory, Center for Machine technology, production, and automation, Agency for Technology Assessment and application, Indonesia

Received: 14 Dec 2020; Received in revised form: 03 Feb 2021; Accepted: 19 Feb 2021; Available online: 22 Mar 2021 (C)2021 The Author(s). Published by Infogain Publication. This is an open access article under the CC BY license (https://creativecommons.org/licenses/by/4.0/).

\begin{abstract}
The industrial robot arm to be analyzed is the Motoman K10S, with configuration has 7 parts, namely Base, Rotary Head, Lower Arm, Upper Arm, Wrist Roll, Wrist Pitch Yaw, and Wrist Twist. The first joint connects the Base section with the Rotary Head (joint range of $340^{\circ}$ or $\pm 170^{\circ}$ ). The second joint connects the Rotary Head section with the Lower Arm (joint range of $240^{\circ}$ or $\pm 120^{\circ}$ ). The third joint connects the Lower Arm section with the Upper Arm (joint range of $275^{\circ}$ or $\pm 137.5^{\circ}$ ). The fourth joint connects the Upper Arm section with the Wrist Roll (joint range of $360^{\circ}$ or $\pm 180^{\circ}$ ). The fifth joint connects the Wrist Roll section with the Wrist Pitch Yaw (joint range of $270^{\circ}$ or $\pm 135^{\circ}$ ). The sixth joint connects the Wrist Pitch Yaw section with the Wrist Twist (joint range of $400^{\circ}$ or $\pm 200^{\circ}$ ). Based on the configuration of the industrial robot arm, further kinematic modeling of the six joints and the placement of the coordinate axis on each joint. Forward and inverse kinematic calculations are made in Matlab software. Then with RoboAnalyzer as a robot arm simulator to verify the results of the calculations.
\end{abstract}

Keywords - industrial robot arm, forward kinematic, inverse kinematic, Matlab, RoboAnalyzer.

\section{INTRODUCTION}

Definition of industrial robots is automatically controlled, reprogrammable, multipurpose manipulator, programmable in three or more axes, which can be either fixed in place or mobile for use in industrial automation applications [1]. An industrial robot is a multipurpose manipulator that is automatically controlled [2]: Three or more axes; (Re)programmable: Translations and Rotations, Movement pattern, and Possibly sensor guided; Can be equipped with different end-effectors for industrial applications: Gripper, Tools, Sensors, etc. Basically, the main components of an industrial arm robots are designed to refer to existing standards as shown in Figure 1 below. In the picture you can see the Base, Rotary Head, Lower
Arm, Upper Arm, Wrist Roll, Wrist Pitch Yaw, and Wrist Twist sections. Base as a holder that will be mounted on the location where the robot is placed. The Rotary Head is a horizontal rotating part ( $\mathrm{S}$ axis) above the Base, and above the Rotary Head there is a Lower Arm section connected to the joint - Waist (waist) that rotates vertically ( $\mathrm{L}$ axis). Upper Arm is the part that is above the Lower Arm and is connected by a joint - Shoulder (shoulder) that rotates vertically ( $\mathrm{U}$ axis). 


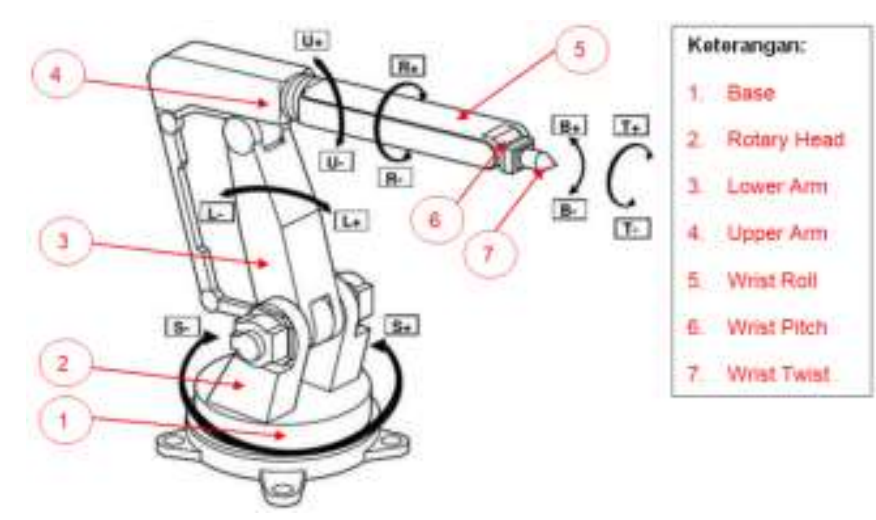

Fig. 1: Industrial Robot Arm Configuration [3]

After the Upper Arm there is the Wrist Roll and it is connected to the joint - Wrist (wrist) which rotates about the axis of the Upper Arm ( $\mathrm{R}$ axis). After the Wrist Roll there is a part of the Wrist Pitch Yaw and it is connected to the joint - Wrist (wrist) that rotates to the perpendicular to the axis of the Upper Arm (axis B). Then at the very end after the Wrist Pitch Yaw there is a part of the Wrist Twist and it is connected with a joint - Wrist (wrist) that rotates about the upper arm axis of the arm (T axis).

The industrial robot configuration that is designed has 6 joints and the names of each joint and their maximumminimum limits can be seen in Table 1 below:

Table 1 Joint Robot Arm Rotation Limitation and Direction

\begin{tabular}{|c|c|c|c|c|c|c|}
\hline No & Joint i & Structur & Max. & Min. & Joint Range & Axis \\
\hline 1 & 1 & Turning & $\begin{array}{c}170^{\circ} \\
(\text { kekiri) }\end{array}$ & $\begin{array}{c}-170^{\circ} \\
(\text { kekanan })\end{array}$ & $340^{\circ}$ & $\mathrm{S}$ \\
\hline 2 & 2 & Lower arm & $\begin{array}{c}120^{\circ} \\
(\text { kebawah })\end{array}$ & $\begin{array}{c}-120^{\circ} \\
\text { (keatas) }\end{array}$ & $240^{\circ}$ & $\mathrm{L}$ \\
\hline 3 & 3 & Upper arm & $\begin{array}{c}137,5^{\circ} \\
(\text { kebawah })\end{array}$ & $\begin{array}{c}-137,5^{\circ} \\
\text { (keatas) }\end{array}$ & $275^{\circ}$ & $\mathrm{U}$ \\
\hline 4 & 4 & Wrist roll & $\begin{array}{c}180^{\circ} \\
(\mathrm{CCW})\end{array}$ & $\begin{array}{c}-180^{\circ} \\
(\mathrm{CW})\end{array}$ & $360^{\circ}$ & $\mathrm{R}$ \\
\hline 5 & 5 & Wrist pitch/yaw & $\begin{array}{c}135^{\circ} \\
(\text { kebawah })\end{array}$ & $\begin{array}{c}-135^{\circ} \\
(\text { keatas })\end{array}$ & $270^{\circ}$ & $\mathrm{B}$ \\
\hline 6 & 6 & Wrist twist & $\begin{array}{c}200^{\circ} \\
(\mathrm{CCW})\end{array}$ & $\begin{array}{c}-200^{\circ} \\
(\mathrm{CW})\end{array}$ & $400^{\circ}$ & $\mathrm{T}$ \\
\hline
\end{tabular}

And in Figure 2 and Figure 3 below, you can see the placement of the coordinate axis (frame) at each joint of the industrial robot arm that is designed, as follows:
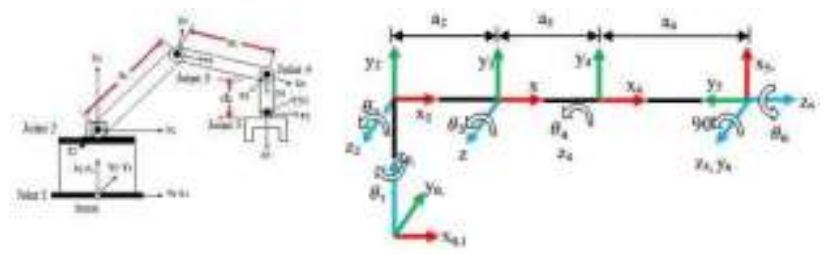

Fig. 2: Industrial Robot Arm Configuration [4]
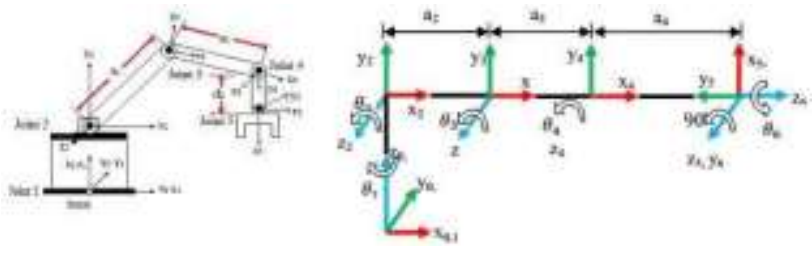

Fig. 3: Robot Arm Construction [4]

\section{KINEMATICS MODELING OF INDUSTRIAL ARM ROBOT}

To be able to determine the orientation and link position of the robot, kinematic modeling is needed. In robotics, kinematic modeling is a form of statement containing a mathematical description of the geometry of a moving robot structure without considering the force causing it. Based on the forward kinematic analysis, the input reference for each actuator can be determined in the form of an angle so that the robot can make movements to achieve the desired orientation and position. Figure 4 shows the placement of the coordinate axis (frame) on the joint simulator arm robot based on the right hand rule.

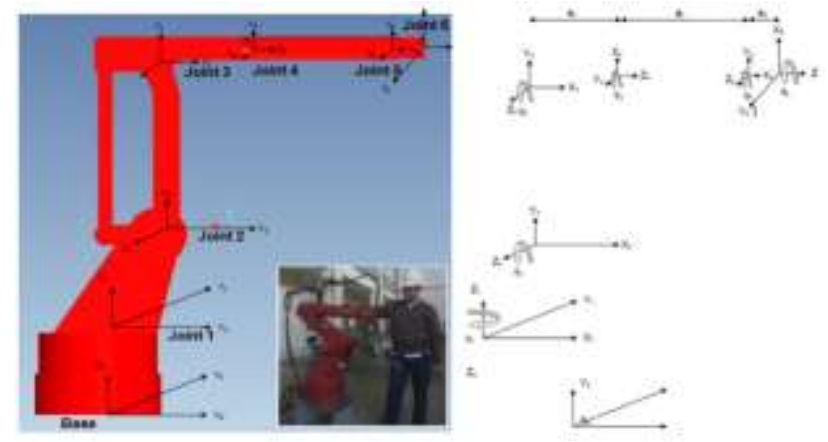

Fig. 4: Coordinate Frames for the Industrial Robot Arm

\section{MATHEMATICAL FORMULATION}

The robot arm simulator consists of several links and joints. Joints are used to connect any existing links where each joint represents one degree of freedom. To describe the translational and rotational relationships between adjacent links, the Denavit Hartenberg (DH) parameter method is used as a matrix method that systematically builds a coordinate system from each link. Table 2 shows the DH parameters of the robot arm simulator. Based on the DH parameter, then the matrix transformation of each frame coordinate can be determined from link $\mathrm{i}$ to $\mathrm{i}+1$ using the following equation: 


$$
{ }_{i-1}^{i-1} T=\left[\begin{array}{cccc}
\cos \theta_{i} & -\sin \theta_{i} \cos \alpha_{i} & \sin \theta_{i} \sin \alpha_{i} & a_{i} \cos \theta_{i} \\
\sin \theta_{i} & \cos \theta_{i} \cos \alpha_{i} & -\cos \theta_{i} \sin \alpha_{i} & a_{i} \sin \theta_{i} \\
0 & \sin \alpha_{i} & \cos \alpha_{i} & d_{i} \\
0 & 0 & 0 & 1
\end{array}\right]
$$

Table 2 DH Parameters for the industrial Robot Arm

\begin{tabular}{|c|c|c|c|c|}
\hline $\mathrm{i}$ & $\alpha_{\mathrm{i}-1}$ & $\mathrm{a}_{\mathrm{i}-1}$ & $\mathrm{~d}_{\mathrm{i}}$ & $\theta_{\mathrm{i}}$ \\
\hline 1 & $0^{\circ}$ & 0 & 0 & $\theta_{1}$ \\
\hline 2 & $90^{\circ}$ & 0 & 0 & $\theta_{2}$ \\
\hline 3 & $0^{\circ}$ & $\mathrm{a}_{1}$ & 0 & $\theta_{3}$ \\
\hline 4 & $0^{\circ}$ & $\mathrm{a}_{2}$ & 0 & $\theta_{4}$ \\
\hline 5 & $0^{\circ}$ & $\mathrm{a}_{3}$ & 0 & $\theta_{5}$ \\
\hline 6 & $90^{\circ}$ & 0 & 0 & $\theta_{6}$ \\
\hline
\end{tabular}

To calculate the forward kinematic, we determine the values a1 $=119 \mathrm{~mm}, \mathrm{a} 2=119 \mathrm{~mm}, \mathrm{a} 3=165 \mathrm{~mm}$ and $\mathrm{a} 4=$ $47.5 \mathrm{~mm}$ based on the link length of the robot arm designed, then determine the sampling angle value $\square \mathrm{i}$, for example $\theta 1=60^{\circ}, \theta 2=60^{\circ}, \theta 3=60^{\circ}, \theta 4=60^{\circ}, \theta 5=90^{\circ}$, and $\theta 6=60^{\circ}$. Furthermore, using the MATLAB software, a matrix transformation equation is obtained which states the orientation matrix and position vector from the base to the end effector as follows:

$$
\begin{aligned}
& { }^{0} T_{5}={ }^{0} T_{1} \cdot{ }^{1} T_{2} \cdot{ }^{2} T_{3} \cdot{ }^{3} T_{4} \cdot{ }^{4} T_{5} \cdot{ }^{5} T_{6} \\
& { }^{0} T_{6}=\left[\begin{array}{cccc} 
& \text { Matriks orientasi } & \text { Vektor posisi } \\
\hdashline 0,0000 & 0,8660 & 0,5 & 28,1997 \\
0,0000 & 0,5000 & -0,8660 & -48,8433 \\
\hdashline-1,0000 & 0 & -0,0000 & 197,8006 \\
\hdashline 0 & 0 & 0 & 1,0000
\end{array}\right]
\end{aligned}
$$

To verify the results of the forward kinematic calculation, the RoboAnalyzer software will be used. By entering the link dimensions and angles with the same value when using MATLAB, the following results will be obtained:

${ }^{0} T_{6}=\left[\begin{array}{cccc}1 E-05 & 0,8660 & 0,4999 & 28,1979 \\ -1,8 E-05 & 0,4999 & -0,8660 & -48,8419 \\ -1,0000 & 0 & 2,1 E-05 & 197,8018 \\ 0 & 0 & 0 & 1,0000\end{array}\right]$

\section{FORWARD KINEMATICS}

The calculation of forward kinematics of the industrial robot arm is carried out either with the help of MATLAB software or with the RoboAnalyzer software for verification. In the early stages, modeling of the robot was carried out, then continued by compiling the $\mathrm{DH}$ Parameters (Denavit-Hatenberg parameter) of the modeled industrial robot arm. And the next step is to calculate forward kinematics based on the initial value or the angle of each joint. The steps from this stage are as follows:

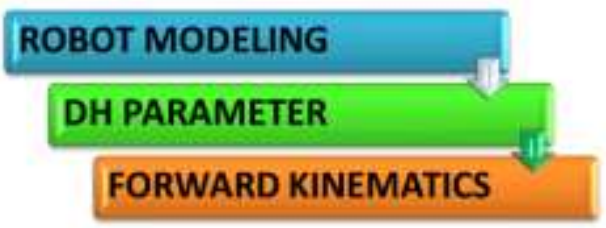

The modeling of the industrial robot arm that is carried out is to determine the position of the $\mathrm{X}-\mathrm{Y}-\mathrm{Z}$ axis for each joint, namely from joint 1 to joint 6 . And for more details, see Figure 3 above.

\subsection{FORWARD KINEMATICS WITH MATLAB}

Based on the industrial robot arm modeling that has been done, the dimensions of each robot link can be determined which can be written in Matlab program. Then enter the initial value or the amount of rotation of each joint in radians written in Matlab program. Then it can display the robot in an X-Y-Z graph and calculate forward kinematics written in Matlab program (Figure 5).

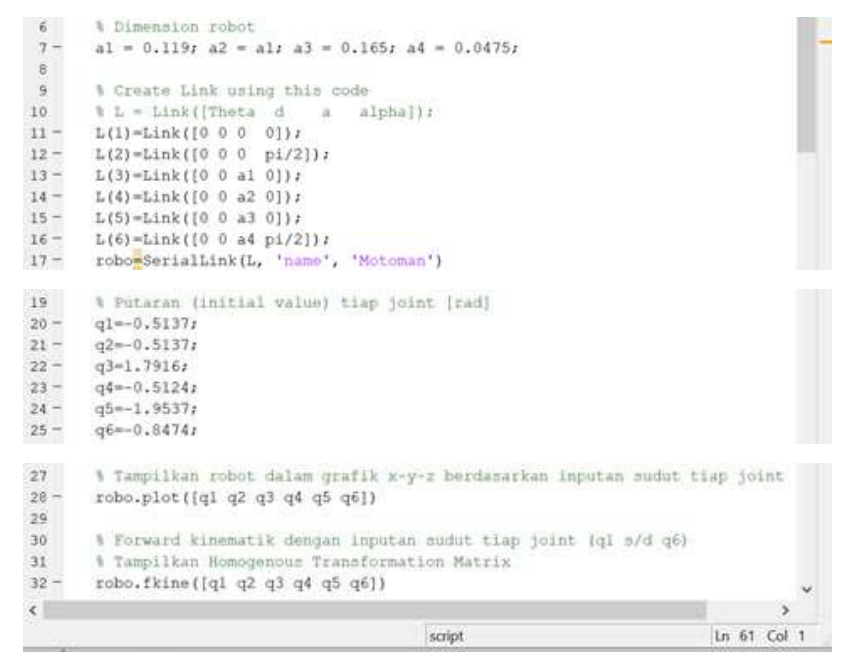

Fig. 5: Coordinate Frames for the Industrial Robot Arm

And the results in matlab can be seen in Figure 6: 


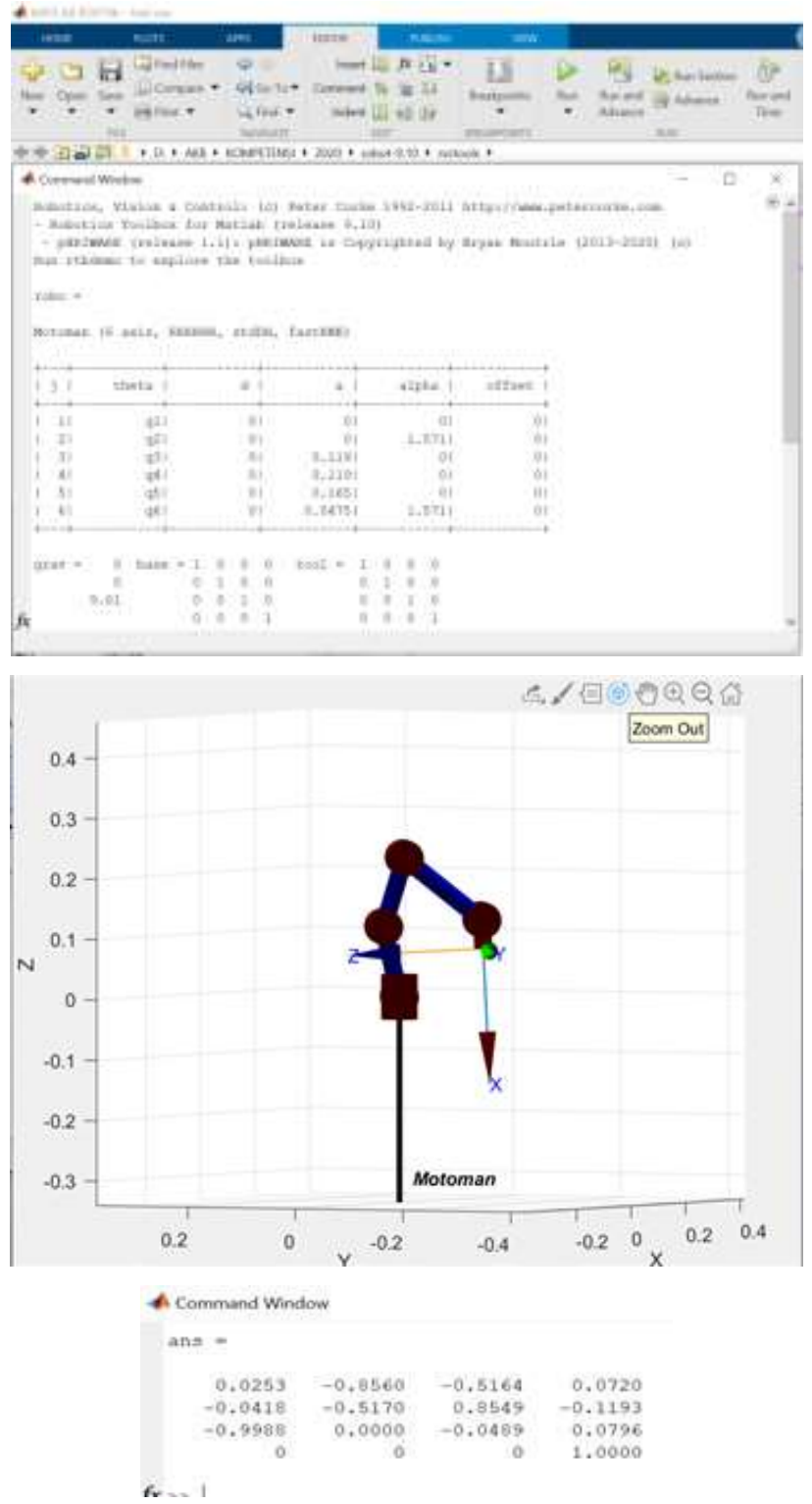

Fig. 6: Result of Forward Kinematics in Matlab

Based on the results obtained above is a homogenous transformation matrix, which contains rotation and translation as well as the position of the end-effector, as follows:

$\mathrm{X}=0.0720 ; \mathrm{Y}=-0.1193 ; \operatorname{dan} \mathrm{Z}=0.0796$.

\subsection{FORWARD KINEMATICS WITH ROBOANALYZER}

And in addition to matlab, forward kinematics calculations can be carried out with the help of RoboAnalyzer software for verification and the results can be seen in Figure 7:

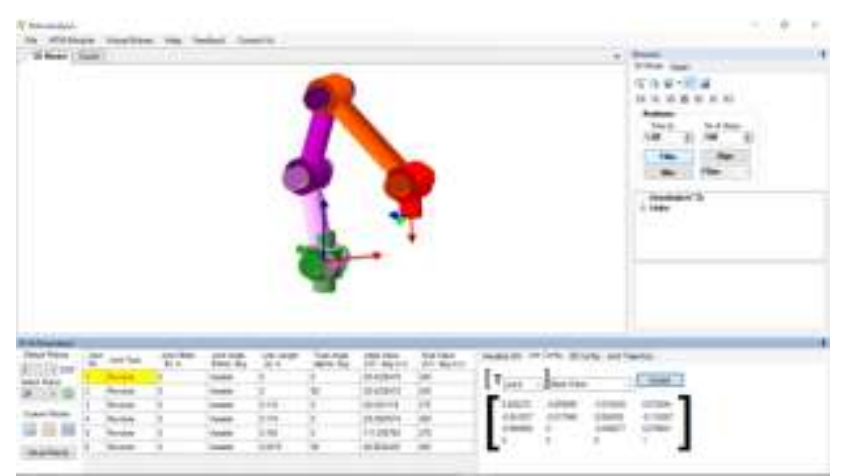

Fig. 7: Simulation of Forward Kinematics in RoboAnalyzer

Based on the results of the calculation of forward kinematics using the RoboAnalyzer software above, it can be seen that the end-effector position is:

$\mathrm{X}=0.072044 ; \mathrm{Y}=-0.119267 ;$ and $\mathrm{Z}=0.079601$.

\section{INVERSE KINEMATICS}

In the inverse kinematics calculation of the industrial robot arm, it is carried out both with the help of MATLAB software and the RoboAnalyzer software for verification. In the early stages, modeling of the robot was carried out, then continued by compiling the DH Parameters (DenavitHatenberg parameter) of the modeled industrial robot arm. And the next step is to calculate inverse kinematics based on the initial value or the angle of each joint. The steps from this stage are as follows:

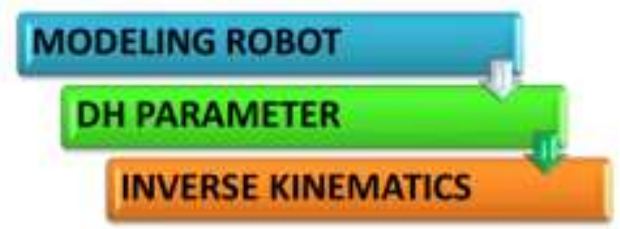

The modeling of the industrial robot arm that is carried out is to determine the position of the $\mathrm{X}-\mathrm{Y}-\mathrm{Z}$ axis for each joint, namely from joint 1 to joint 6 . And for more details, see Figure 3 above.

\subsection{INVERSE KINEMATICS WITH MATLAB}

Based on the industrial robot arm modeling that has been done, the dimensions of each robot link can be determined which can be written in Matlab program. Then enter the position of the end effector, which is the translation on the $\mathrm{X}, \mathrm{Y}$, and $\mathrm{Z}$ axes in $\mathrm{mm}$ and the rotation on the $\mathrm{X}, \mathrm{Y}$, and $\mathrm{Z}$ axes in degrees written in Matlab program. Then the inverse kinematics calculation can be done and display the robot in an X-Y-Z graph written in Matlab program (Figure 8). 


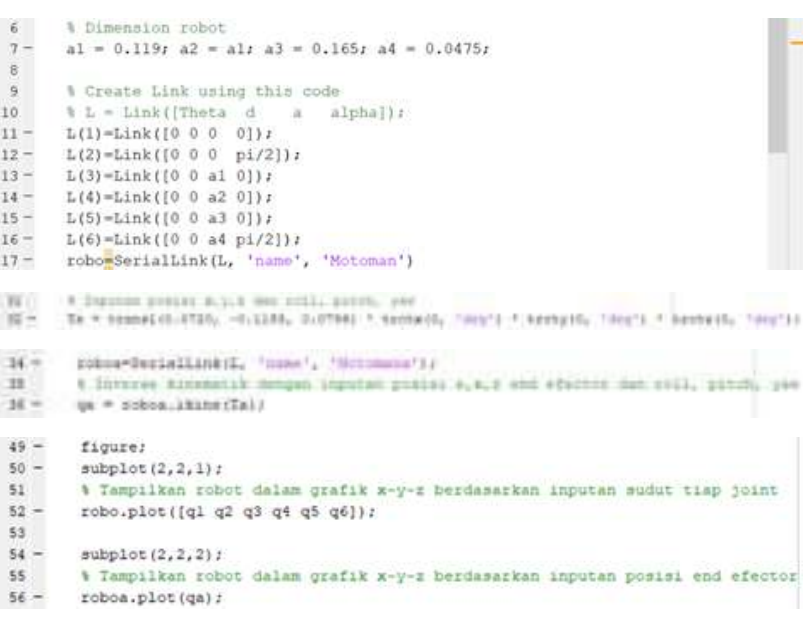

Fig. 8: Matlab Program for Forward Kinematics

And the results in matlab can be seen in Figure 9:

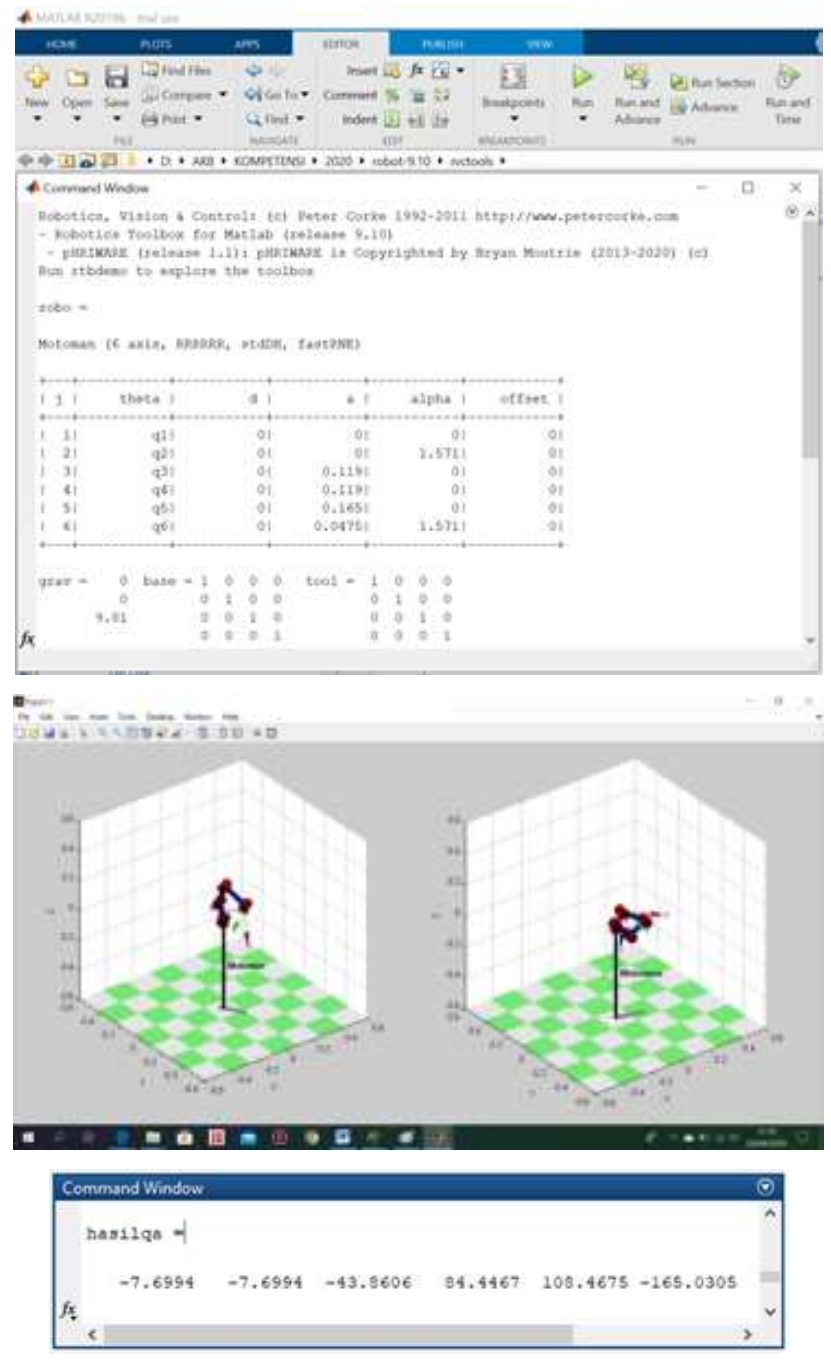

Fig. 9: Result of Inverse Kinematics in Matlab
Based on the results obtained above, the amount of rotation of each joint is in degrees, as follows:

$\mathrm{q} 1=-7.6994 ; \mathrm{q} 2=-7.6994 ; \mathrm{q} 3=-43.8606 ;$

$\mathrm{q} 4=84.4467 ; \mathrm{q} 5=108.4675 ;$ and $\mathrm{q} 6=-165.0305$

\section{V.1. INVERSE KINEMATICS WITH ROBOANALYZER}

And in addition to matlab, inverse kinematics calculations can be done with the help of RoboAnalyzer software for verification and the results can be seen in Figure 10:

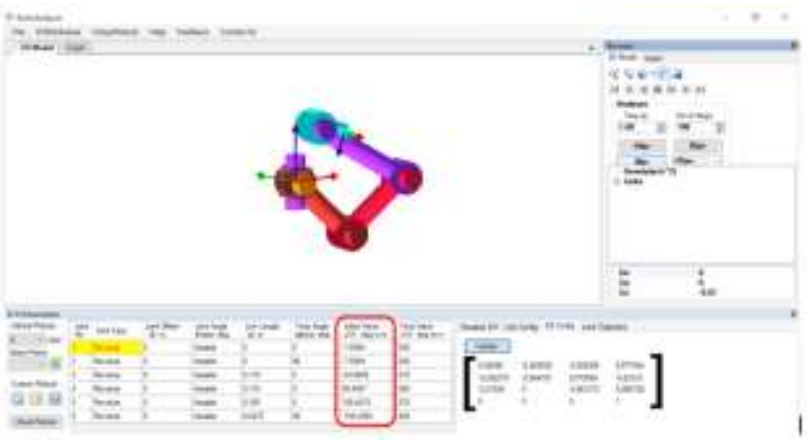

Fig. 10: Simulation of Inverse Kinematics in RoboAnalyzer

Based on the results of inverse kinematics calculations with the RoboAnalyzer software above, it can be seen that the rotation rate of each joint in radians is:

$\mathrm{q} 1=-7.6994 ; \mathrm{q} 2=-7.6994 ; \mathrm{q} 3=-43.8606 ;$

$\mathrm{q} 4=84.4467 ; \mathrm{q} 5=108.4675 ;$ and $\mathrm{q} 6=-165.0305$

\section{RESULTS AND DISCUSSION}

Based on the simulation results of forward and inverse kinematics in Matlab and RoboAnalyzer for industrial robot arm. The results of simulation forward kinematics in RoboAnalyzer is almost the same as that generated from the Matlab program, And the results of simulation inverse kinematics in RoboAnalyzer is almost the same as that generated from the matlab program.

\section{CONCLUSION}

Based on the paper results can be concluded as follows:

1. The forward kinematics calculations were successfully carried out in Matlab program and RoboAnalyzer software.

2. The inverse kinematics calculations were successfully carried out in Matlab program and RoboAnalyzer software.

3. The kinematic simulation that has been done can be 
used as the basis for controlling the designed industrial arm robot.

\section{ACKNOWLEDGEMENTS}

For research on industrial arm robot theme in the world of manufacturing, the authors suggest the following research:

1. Industrial robotic arm modeling and the basics of kinematics can be developed into a program to control robots in the welding process.

2. The use of more than one industrial arm robot with the program algorithms to simulate a manufacturing process.

3. Combining the Matlab program with the $\mathrm{C}$ programming language in controlling industrial robot arms.An acknowledgement section may be presented after the conclusion, if desired.

\section{REFERENCES}

[1] ISO 8373:2012 definition of industrial robots

[2] Dr. -Ing. Dipl.-Wirt.Ing. Tim Detert, Introduction to Industrial Robotics and Current Research for Industry 4.0, Department of Mechanism Theory and Dynamic of Machines and Robotics, RWTH Aachen University

[3] MOTOMAN K1OS INSTRUCTION MANUAL, MOTOMAN ROBOTICS, 1994

[4] Munadi, ANALISA FORWARD KINEMATIC PADA SIMULATOR ARM ROBOT 5 DOF YANG MENGINTEGRASIKAN MIKROKONTROLER ARDUINO-UNO DAN LABVIEW, Laboratorium Komputasi, Jurusan Teknik Mesin, Fakultas Teknik, Universitas Diponegoro

[5] Firmansyah dkk., Perancangan Lengan Robot 5 Derajat Kebebasan, Jurnal Rekayasa Elektrika Vol. 11, No. 2, Oktober 2014, hal. 69-72 